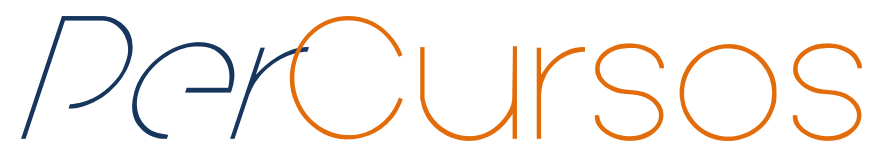

\title{
Quando a violência é perpetrada pelo Estado: expondo a fratura do direito à manifestação pacífica
}

\begin{abstract}
Resumo
O engajamento político em manifestações é um direito duramente conquistado em solo brasileiro e a violação dele configura-se como grave violência de Estado, sendo inadmissível em uma sociedade que se pretende justa, igualitária e democrática. O presente texto trata-se de uma cartografia clínico-política referente aos desdobramentos subjetivos decorrentes de um caso de violência física, psicológica e de negligência perpetrados por policiais militares contra um dos sujeitos envolvidos em manifestação pública realizada por cidadãos residentes em Florianópolis, em janeiro de 2014. A procura pelo serviço de atendimento psicológico ocorreu, por parte da vítima, após o episódio de violência. Foram realizadas onze sessões de acolhimento e apoio psicológico com o manifestante e coautor do presente trabalho, subsidiando a escrita de um parecer juntado ao processo judicial movido pela vítima. O trabalho psicoterapêutico buscou mapear elementos subjetivos vinculados ao episódio de violência, participando do processo de resiliência e ressisgnificação da experiência sofrida, configurando-se a dimensão ético-política da clínica. A coescrita do presente texto é um dos efeitos (re)inventivos resultantes da psicoterapia, inaugurando o lançamento dos autores no engajamento em uma nova e cara causa: a do direito à manifestação política.
\end{abstract}

Palavras-chave: Violência Policial. Manifestações Públicas. Subjetividade.

\author{
Marcelo Venturi \\ Doutorando em Geografia na \\ Universidade Federal de Santa \\ Catarina - UFSC. Engenheiro \\ Agrônomo da UFSC. \\ Brasil \\ marcelo.venturi@ufsc.br \\ Renata Orlandi \\ Doutora em Psicologia pela \\ Universidade Federal de Santa \\ Catarina - UFSC. Professora da \\ Universidade Federal de Santa \\ Catarina - UFSC. \\ Brasil \\ renata.orlandi@ufsc.br

\section{Rogério Machado Rosa} \\ Doutor em Educação pela \\ Universidade Federal de Santa \\ Catarina - UFSC. Professor da \\ Universidade do Sul de Santa \\ Catarina - UNISUL. \\ Brasil \\ esquizorrosa@gmail.com
}

\section{Para citar este artigo:}

VENTURI, Marcelo; ORLANDI, Renata; ROSA, Rogério Machado. Quando a violência é perpetrada pelo Estado: expondo a fratura do direito à manifestação pacífica. Revista PerCursos, Florianópolis, v. 18, n.37, p. 194 - 211, maio/ago. 2017.

\section{DOI: $10.5965 / 1984724618372017194$}

http://dx.doi.org/10.5965/1984724618372017194 


\title{
When violence is perpetrated by the state: exposing the fracture of the right to peaceful manifestation
}

\begin{abstract}
The political engagement in protests is a right hard-won on Brazilian soil and its violation is configured as a serious state violence, being inadmissible in a society supposedly just, egalitarian and democratic. This text is a clinical-political cartography referring to the subjective consequences arising from a case of physical and psychological violence, and negligence perpetrated by military police against one of the subjects involved in a public demonstration performed by residents in Florianópolis, in January 2014. By iniciative of the own victim, a psychological care service was sought in order of supplying his demand after the violent episode. Eleven reception and psychological support sessions were were held with the demonstrator and co-author of this paper, subsidizing the writing of an report included in the lawsuit filed by the victim. The psychotherapeutic work aimed to map subjective elements related to the episode of violence, participating in the resilience and redefinition of the process of painful experience, setting the ethical and political dimension of the clinic. The co-writing of this text is one of the (re)inventive effects resulting from psychotherapy, inaugurating the launch of the authors on the engagement in a new and strong cause: the right of political demonstration.
\end{abstract}

Keywords: Police Violence. Public Manifestations. Subjectivity.. 
O engajamento político em manifestações é um direito duramente conquistado em solo brasileiro e a violação dele configura-se como grave violência de Estado, sendo inadmissível em uma sociedade que se pretende justa, igualitária e democrática. No país, o emprego das forças policiais na repressão dessa modalidade de atuação política está diretamente relacionado à herança da ditadura militar, partindo-se do pressuposto de que a defesa da nação justifica e legitima a brutalidade perpetrada a seu serviço (GASPARI, 2002; GUIMARÃES, TORRES, FARIA, 2005; LIMA, SINHORETTO, BUENO, 2015). Pela complexidade de sua natureza, a violência aqui é compreendica como figura de desordem ${ }^{1}$, e que por isso reúne em si paradoxos, ambiguidades, fluidez e multiplicidades expressivas, características típicas dos movimentos de (des)organização das civilizações.

Nesse sentido, a relação de poder fascista está atrelada ao desejo de exercer sobre o outro a dominação e a exploração que é imposta sobre o fascista (FOUCAULT, 1979). Modos de vida fascistas pressupõem o privilégio de legitimar, naturalizar e hierarquizar distinções segregadoras e excludentes que reduzem o outro aos polos da utilidade ou da inadequação ao normativo. Visando não compactuar com a naturalização dos fascismos que nos assolam na contemporaneidade, narraremos aqui a vivência de um sujeito que foi enquadrado como inútil e inadequado aos olhos do poder policial.

A presente cartografia ${ }^{2}$ refere-se aos desdobramentos subjetivos decorrentes de grave violência física, psicológica e de negligência perpetrados por policiais militares

\footnotetext{
1 Para Georges Balandier (1997), o social apresenta-se sob a forma de configurações presididas pelo imaginário que o constitui e dá sentido, assim, todo movimento de ordem e desordem que também compõe o social manifesta-se figurativamente, legitimando os grandes emblemas das sociedades contemporâneas.

${ }^{2}$ A cartografia e a escrita cartográfica dizem de uma busca por um salto do atual para o virtual, algo entre o que se é e o que se pode vir a ser. Por isso, não se atém às relações entre variáveis e de causa e efeito entre os fenômenos. A cartografia e a escrita cartográfica referem-se a um estilo de escrever e de pesquisar itinerantes, em trânsito e sem endereços e endereçamentos fixos. Nessa direção, destacam-se as idéias de Moura \& Hernandez (2012) quando argumentam que [...] a cartografia trata da concepção, produção, difusão, utilização e estudo dos mapas. Inventando um mundo e seus lugares, interpretando à sua maneira o espaço, há casos em que ela é aplicada como método de acompanhamento para traçar percursos poéticos, sendo aquilo que força a pensar e ver o todo do processo do artista pesquisador, dando-se como possibilidade de caminho a ser traçado no trabalho, como uma atenção voltada ao processo em curso. Entendendo que o método cartográfico convoca a um exercício cognitivo peculiar do pesquisador, uma vez que, estando voltado para o traçado de um campo problemático, requer uma cognição muito mais capaz de inventar o mundo do que reconhecê-lo (2012, p. 2).
} 
contra um dos coautores desse estudo. A vítima estava em período de férias na ocasião do episódio, ocorrido no dia 6 de janeiro de 2014, em frente à Câmara de Vereadores, em meio a uma manifestação pública realizada por cidadãos residentes em Florianópolis. Os manifestantes protestavam em defesa de um plano diretor municipal ambientalmente equilibrado, bem como pela sistematização do mesmo por meio de um processo horizontal, humano, democrático e participativo, envolvendo toda a sociedade. Haja vista os seus conhecimentos técnicos e seu compromisso para com a ampliação do debate sobre o tema, o autor/entrevistado manifestava-se no local quando então, em momento de tensão entre policiais e manifestantes, ficou posicionado entre os dois grupos comportando-se de maneira visivelmente pacificadora e conciliatória, com as mãos para o alto. No entanto, foi severamente violentado com um cassetete pelas costas, o qual atingiu o seu crânio fraturando a sua face e o seu direito ao exercício da cidadania.

Abordaremos, aqui, o processo de avaliação e apoio psicológico desenvolvido a partir de uma demanda do manifestante/agredido. Este procedimento foi solicitado em razão do sofrimento experienciado após ter sofrido esta grave situação de violência policial. Ao longo dos meses que se seguiram à vivência dessa adversidade, paralelos às intercorrências médicas, farmacológicas, psicológicas, familiares, comunitárias, laborais, midiáticas e jurídicas vivenciadas pela vítima, ocorreram em solo brasileiro novas manifestações políticas marcadas por severas intervenções policiais, gerando grande mobilização ético-política nos três autores desse trabalho, os quais decidiram tornar públicos aspectos psicológicos dessa vivência, haja vista a morosidade do trâmite judicial e a urgência em promover debates sobre o tema.

Logo, somos três a desenvolver esta escritura. Uma psicóloga forense, responsável pelos encaminhamentos jurídicos do caso em tela; um psicólogo clínico, que assumiu a incumbência de acompanhar e avaliar psicologicamente a vítima; e a própria vítima da violência policial em questão, que durante o acompanhamento psicológico decidiu dar visibilidade acadêmica ao seu caso como forma de se posicionar política e eticamente perante o tema.

Escrever e publicar uma reflexão crítica tomando sua experiência autobiográfica como ponto de partida, foi, assim, uma estratégia adotada para anunciação de uma 
resposta ao Estado, um chamado ao estranhamento e à problematização do atual sistema de segurança do nosso país, com seus paradoxos e contradições. A opção em escrever no plural, a seis mãos, diz de um posicionamento político nosso que se pauta no entendimento de que toda ética, necessariamennte, nos convoca à responsabilidade, isto é, a dar uma resposta ao outro (LÈVINAS, 1997), e, neste caso, o fazemos sob a forma de assinatura do nosso posicionamento em torno da recusa de qualquer forma de violência.

A partir do primeiro registro escrito que, inicialmente, configurou-se como um parecer psicológico ${ }^{3}$, o qual foi juntado ao processo judicial movido pelo autor/entrevistado, sistematizou-se o presente artigo. Destaca-se que a escrita a seis mãos foi possível em razão do vínculo ${ }^{4}$ engendrado entre os autores e o sentimento compartilhado de perplexidade diante da banalização, sobretudo por parte do Estado e da mídia, dessas atrocidades. Espera-se que o presente trabalho possa subsidiar mudanças no processo de formação policial de modo a colaborar em processos reflexivos voltados à garantia da igualdade, justiça social, segurança e cidadania a todos/as brasileiros(as) (Lima, Sinhoretto e Bueno, 2015).

\section{A cartografia como método?}

$\mathrm{Na}$ travessia metodológica realizou-se um estudo psicológico das peças processuais e um processo de entrevista psicológica com a vítima/coautor. O processo de realização das onze sessões dedicadas ao apoio, acolhimento, avaliação psicológica e escrita do respectivo parecer, mobilizou nos psicólogos acionados, assim como no entrevistado, uma reflexão sobre a violência do Estado, movimento esse que dá colorido à citação de Morin sobre a metodologia científica: "método como atividade pensante do sujeito vivente, não-abstrato. Um sujeito capaz de aprender, inventar e criar em e durante o seu caminho" (MORIN, 2003, p. 18).

\footnotetext{
${ }^{3}$ Informe Psicológico elaborado conforme determinações da Resolução CFP 07/2033.

${ }^{4}$ Em respeito à dimensão ética do vínculo formado entre psicólogos e entrevistado, ressalta-se a figura do rapport, que, no contexto da intervenção psicológica, está relacionado ao primeiro contato voltado para o estabelecimento de um encontro acolhedor, marcado pela dimensão afetiva e confiança engendradas entre os envolvidos no processo de entrevista (Raymundo, 2000), repercutindo em toda a atividade de campo e devolução de dados.
} 
Seguimos as reflexões metodológicas com o seguinte questionamento:

Mas quem disse que a cartografia só pode representar fronteiras e não construir imagens das relações e dos entrelaçamentos, dos caminhos e fugas de um labirinto? (MARTíN-BARBAIRO, 2004, p. 147)

Tal provocação de Martín-Barbairo é um convite à subversão da noção tradicional e engessada de "método". Propusemos aqui uma reflexão cartográfica no intento de “[...] captar algo da experiência das pessoas" (FONSECA, 1999, p. 10), sendo tais pessoas os próprios autores, os quais se lançaram no labirinto da compreensão de um episódio violento em seus desdobramentos, ao longo das idas de vindas do caminho percorrido/construído. Um encontro de alteridades na alterização, travessia por diferentes caminhos e maneiras de sentir-ser-estar-afetar (n)o mundo.

Elegeu-se a postura cartográfica como estratégia para nos aproximar do universo conceitual do outro, dos labirintos semióticos que se cruzam nos encontros investigativos pautados pelas relações de alteridade, as quais intensificam aproximações intersubjetivas no processo criativo de saberes. O termo cartografia dialoga com a noção de "mapa", transcendendo à topologia quantitativa, que limita o território estática e rigidamente. No método cartográfico, buscamos acompanhar, observar atentamente, capturar e registrar densamente as mudanças no terreno, reconhecendo a nossa participação nos acontecimentos cartografados, nesse caso, um episódio marcado pela violência do Estado.

Sendo assim, partimos da premissa de que os cartógrafos reconhecem a sua participação no fenômeno investigado, sua condição de testemunhas do próprio movimento de estar nele, observando-o, sentindo-o, registrando-o e conhecendo-o. $\mathrm{O}$ cartógrafo admite a intersubjetividade e produz saberes ao atentar para os desdobramentos de sua presença no acontecimento investigado. O cartógrafo não se ilude com a fantasia da neutralidade, tem a pretensão, justamente, de lançar-se em queda livre ao encontro visceral com o acontecimento mapeado, aí residindo o rigor do seu fazer científico. O cartógrafo, portanto, reflete sobre a sua mobilização diante dos 
acontecimentos que o afetam. Segundo Deleuze (1997, p. 169).) "ada vez que um corpo convém com o nosso e aumenta nossa potência, uma noção comum aos dois corpos pode ser formada de onde decorrerão uma ordem e um encadeamento ativos das afecções".

A perspectiva cartográfica atua como uma espécie de dobra metodológica a qual, ao dialogar com dispositivos teóricos atrelados a distintas esferas do saber, suscita nos pesquisadores um estado de outramento; favorece-lhes habitar em novos espaços e modos de ser-estar em relação consigo e com o outro. No ato de pesquisa, cartógrafos envolvem seu corpo no fenômeno atentamente observado e se implicam com os acontecimentos nas fronteiras de suas (im)possibilidades. Portanto, não poderiam, nem desejariam, dessa experiência sair ilesos. Nenhum dos três autores do presente trabalho saiu ileso à experiência e estão aqui "dando a outra face" ao debate sobre o tema, contudo, agora, de frente para o acontecimento, subvertendo as suas fronteiras.

Reitera-se que o convite dirigido à vítima para compor a autoria do presente estudo tem sentido ético, pois afirma um modo de agir e pensar comprometido com a garantia de direitos e com a emancipação dos sujeitos que culmina com a resistência às mais variadas formas de expressão das violências (SOUSA, 2011). Entendemos que a condição sine qua non para a experimentação da ética no fazer científico está atrelada à legitimação da alteridade radical, na perspectiva de Lèvinas (1997). Nesse contexto, a ética é tecida no processo de manifestação da verdade do(a) outro(a), na afirmação e acolhida da sua presença radical situada em relação ao seu referencial político, cultural e/ou subjetivo (hegemônico ou minoritário).

\section{Discussão sobre os acontecimentos cartografados}

Considera-se violência o emprego intencional de força física ou poder, efetuado ou ameaçado, contra si, contra outra pessoa, grupo ou comunidade, resultando ou podendo resultar em lesão, morte, comprometimento psicológico, défice no desenvolvimento pessoal ou privação ( ORGANIZAÇÃO MUNDIAL DA SAÚDE, 2003). Chauí (1985) problematiza o conceito de violência a partir de duas perspectivas: a da assimetria e a da 
coisificação do outro. A primeira perspectiva diz respeito à conversão de uma diferença, colocada como uma assimetria que possibilita uma relação hierárquica desigual, visando a dominação, a exploração e a opressão. A segunda perspectiva refere-se à ação que trata um sujeito não como humano, mas como coisa, objeto silenciado, inerte e passivo. Segundo a autora, quando a fala e a atividade do outro é impedida ou calada, há violência.

A violência física engloba todo o tipo de ação ou omissão que coloca em risco ou causa dano à integridade física de uma pessoa. Sobre a violência física sofrida pela vítima em questão, destaca-se o sofrimento atrelado à situação de espancamento e às decorrentes lesões nos olhos 5 , testa, pescoço e ombros, em especial à fratura da face, assim como ao intenso desconforto vinculado à submissão de procedimentos cirúrgicos e pós-cirúrgicos e a exposição à toxidade das medicações prescritas. Esse conjunto de violências físicas e as dores vivenciadas são sintetizados pelo entrevistado/autor em um único adjetivo: “desnecessário", na medida em que, tal como consta nos autos, é evidente que $\mathrm{o}$ ato lesivo consistiu em um abuso do poder policial. Portanto, tal abuso pode ser pensado a partir da perspectiva em que

uma relação de violência age sobre um corpo, sobre as coisas; ela força, ela submete, ela quebra, ela destrói; ela fecha todas as possibili-dades; não tem, portanto, junto de si, outro polo senão aquele da pas-sividade. O que configura o uso da força, da coerção e a produção de dano em relação ao outro: um ato de excesso presente nas relações de poder. (FOUCAULT, 1995, p. 243)

A violência é um fenômeno complexo, multifacetado e polissêmico, tornando qualquer tentativa de categorização de sua trama limitada. É mister frisar que tais

\footnotetext{
${ }^{5}$ Durante o processo de elaboração e submissão desse trabalho, a vítima estava se recuperando do quarto procedimento cirúrgico, nesse caso, voltado para a recuperação da visão do olho atingido. Importante ressaltar que a perda da visão esquerda repercutiu em dificuldades em seu cotidiano, tanto para se deslocar como para realizar atividades laborais e sociais, incluindo pequenos acidentes atrelados à cegueira parcial. As lesões restantes em sua visão e auto-estima evocam a todo o momento a violência sofrida, ainda que o sentimento de revolta se manifeste de maneira gradativamente mais sutil, havendo uma forte intenção de fazer algo do sofrimento, transformando-o em algo que faça sentido em sua trajetória, tendo o presente trabalho, por exemplo, uma motivação sublimatória.
} 
categorias costumam ser cumulativas e delineadas para fins didáticos e de melhor compreensão do fenômeno (FALEIROS; FALEIROS, 2007) e manifestam-se de várias maneiras (simbólica, estrutural, física, psicológica, sexual, tráfico de pessoas, exploração do trabalho, negligência), por diferentes atores (Estado, conhecidos, desconhecidos, familiares, amigos, vizinhos, mídia...), haja vista vários fatores (gênero, classe, etnia, geração, grupo de pertença, religião) e lugares (casa, rua, escola, trabalho, igreja, comunidade) que a constituem.

Em se tratando da violência psicológica, esta consiste na agressão emocional que engloba a ameaça, a insegurança, a rejeição, a humilhação e a discriminação. $O$ entrevistado também foi involuntariamente exposto ao estresse decorrente de prejuízo financeiro relacionado a atendimentos médicos e procedimentos cirúrgicos e póscirúrgicos, à perda do direito de gozar as suas férias plenamente, ao temor de uma deficiência visual e deformidade crônica na face e, sobretudo, de alteração da maior marca identitária de um sujeito, a sua expressão facial, assim como a intensa exposição pública, tendo a sua imagem tendenciosamente vinculada ao vandalismo por meios de comunicação acríticos. Além disso, a vítima teve o seu cotidiano e seus modos de vida impactados, lidando com mudanças drásticas em sua rotina durante a sua recuperação e com a possibilidade de impactos permanentes em seu corpo e estilo de vida, já que praticava esportes, assim como realizava atividades sociais e laborais que foram inviabilizadas pelo comprometimento de sua visão.

$\mathrm{Na}$ violência psicológica, entre essa série de desdobramentos, destacamos o estresse pós-traumático ${ }^{6}, C_{1 D} .10=$ F43.1/DSM.IV = 309.81, que consiste no desenvolvimento de sintomas característicos após a vivência de um evento estressor de severa magnitude, envolvendo a experiência pessoal direta de um evento real ou ameaçador que envolve morte, sério ferimento ou outra ameaça à própria integridade física, tal como ocorreu com o entrevistado. Com relação ao seu caso, foram mapeados sintomas de insônia e

\footnotetext{
${ }^{6}$ Destacamos o fato de que o sofrimento vivenciado por Marcelo é singular e produto de uma trama de fatores e experiências que antecedem e se seguem aos acontecimentos. Portanto, o conceito de estresse pós-traumático foi empregado numa perspectiva crítica e apenas para fins didáticos, terminologia essa que se pretende compreensível ao público leigo no campo da Psicologia, mais especificamente, ao poder judiciário.
} 
ansiedade, pensamentos persecutórios em relação à polícia, a recorrência do temor da morte, o constrangimento de ter sua imagem exposta nas redes sociais e o impacto do episódio de violência na rede de apoio do autor/entrevistado. Destacam-se aqui os desdobramentos do evento na vida emocional da sua companheira no período narrado, a qual passou a ter crises de ansiedade e intenso medo de perdê-lo, havendo também ruídos no relacionamento amoroso vinculados aos prejuízos na autoestima da vítima causados pelas lesões, deformidades, cicatrizes e inchaço na face decorrentes da agressão e cirurgias subsequentes. Tais adversidades são expressões da violência psicológica e do sofrimento ético-político que será problematizado a seguir.

Entende-se que os fenômenos psicológicos podem ser compreendidos pelos processos de significação, pela condição de cada sujeito atribuir sentidos aos seus modos de ser e à convivência em sociedade, sendo as relações sociais interrogadas para a compreensão da dimensão psicológica. Assim, a corporeidade dos sujeitos, que é biológica, semiótica, afetiva e histórico-social, é, fundamentalmente, ética. Segundo Heller (1972) e Sawaia (1995), a ética não é absoluta nem compreensível em si, não tem objetividade natural e sim social, isto é, depende das atividades dos homens. A ética é a expressão e o resultado das relações sociais e das condições históricas. Os fenômenos psicossociais são considerados imanentemente éticos.

Para Sawaia (1999), o sofrimento ético-político retrata a vivência cotidiana das questões sociais dominantes em cada contexto histórico, especialmente, a exclusão e a dor engendradas no cenário social e impostas a quem é tratado como inferior, subalterno, sem valor, apêndice inútil da sociedade. Portanto, o sujeito vive o sofrimento, sente e sofre individualmente, mas tal sofrimento não tem origem individual, pois é constituído no campo das intersubjetividades configuradas social e historicamente. Particularmente, no caso da vítima, o sofrimento ético-político está intimamente relacionado à violência física, à violência psicológica e à negligência que compõem a trama de violações de direitos humanos perpetrados pelos servidores públicos da polícia militar em tela, configurando-se, portanto, como um lamentável e emblemático exemplo de violência institucional. 
A transição para a democracia em solo brasileiro parece ter aberto espaço para o debate sobre a violência policial, entretanto, a fragilidade de nossa organização política, a marcante desigualdade social, a intolerância à diversidade, a forte presença da violência que se configura como um importante elemento de nosso cenário cultural, assim como os efeitos da globalização econômica engendram dificuldades no processo de enfrentamento e ressignificação de práticas abusivas naturalizadas e marcadas pelo fascismo cometido por policiais no cumprimento do mandato legal (NETO, 1999; GUIMARÃES, TORRES, FARIA, 2005; LIMA, SINHORETTO; BUENO, 2015).

A violência institucional é aquela cometida contra os cidadãos por representantes do Estado. Toda violência é grave, porém, as violações cometidas por agentes do Estado ou no interior de espaços em que o Estado é responsável direto são agravadas na medida em que este deve ser o maior encarregado pela garantia dos direitos fundamentais dos cidadãos. A indiferença do Estado em relação aos dramas que atingem milhões de pessoas tem criado movimentos sociais voltados à reivindicação de direitos. Aí estão os sem-terra, os sem-teto, os sem-emprego, os sem-escola, os sem-saúde, enfim, os excluídos dos bens elementares e os politicamente engajados na luta pela efetivação de direitos, entre eles, o direito à participação nas decisões políticas de um Estado supostamente democrático.

Tais movimentos são considerados "hostis" e "agressivos" pelo Estado e pelas camadas médias e altas da população, na medida em que representam, pelo menos potencialmente, uma suposta ameaça à ordem política estabelecida, uma ameaça ao status quo. Qualquer ação promovida por esses movimentos frequentemente tende a ser interpretada como "perigosa”, “nociva”, “inquietante e inquietadora” por parte do Estado e seus representantes, o que culmina, via de regra, em ações de repressão e cerceamento da liberdade de expressão e exercício da cidadania. Nesse sentido, a violência cometida pela instituição tem alvos bem delineados cuja vulnerabilidade é atravessada por questões de classe, gênero, raça, geração, orientação sexual e política (SANTOS, 1997; CASTRO, ABRAMOVAY, 2002; LIMA, SINHORETTO, BUENO, 2015).

Portanto, a violência institucional, aquela promovida, desenvolvida e estimulada pelo próprio Estado, apresenta uma dupla via de iníqua realização: a primeira, e 
gravíssima, a de negar o acesso dos majoritários segmentos da população aos bens de vida e à participação nas decisões públicas; a segunda, e não menos grave, a de estigmatizar, rotular como "delinquente", "criminosa” ou "atentatória à ordem pública” qualquer ação de manifestantes e movimentos organizados. Assim, essa modalidade de violência é compreendida como aquela praticada por instituições prestadoras de serviços públicos como hospitais, escolas, postos de saúde, bancos, delegacias, fóruns, entre outros. É praticada por agentes que deveriam colaborar na efetivação de direitos promovendo a assistência, o cuidado e a atenção humanizada aos cidadãos. A violência institucional, então, é uma prática incompatível com a vivência ética em sociedade, pois fere diretamente os direitos constitucionais e a dignidade da pessoa humana.

O coautor/entrevistado, na ocasião em que sofreu violência institucional, foi lesado em seu direito à integridade física, psicológica e de participação no processo democrático, sendo tal violação ilegítima, injusta e ilegal. No processo movido pela corregedoria de polícia, o policial agressor foi declarado inocente em primeira instância. Diante dessa notícia, a vítima recorreu ao Ministério Público e surpreendeu-se ao saber que, anteriormente ao seu pedido, o caso havia sido encaminhado por procuradores e o policial foi nessa esfera declarado culpado, sendo penalizado com o pagamento de uma cesta básica mensalmente por um ano, valor simbólico comparado aos gastos com os tratamentos demandados pela agressão.

O processo cível segue tramitando enquanto o entrevistado coleciona contas e exames atrelados à violência policial. Em primeira instância, o processo gerou uma simbólica indenização no valor de 5.000 reais, a qual não cobre nem sequer parte dos custos ligados a consultas, exames e medicamentos; o advogado responsável pelo caso está recorrendo em segunda instância. Em relação à saúde física, a visão comprometida no episódio ainda não foi recuperada, demandando a submissão a procedimentos médicos bimestrais. Com relação à dimensão subjetiva, o autor/vítima verificou uma série de avanços relacionados ao seu bem-estar psicológico, ainda que identifique forte conexão entre a agressão sofrida e o término de seu relacionamento amoroso que contabilizava dez anos, haja vista a onda de choque emocional sofrida por ele e sua, até então, companheira. 
É válido salientar que o Ministério Público Federal revogou o Plano Diretor do Município de Florianópolis aprovado pelos vereadores naquela ocasião e determinou a realização de audiências públicas e nova votação do referido documento, legitimando a revindicação dos manifestantes entre os quais se encontrava a vítima/coautor. Para muito além da investigação e punição dos casos de violência policial, destacamos aqui a importância do investimento em processos educativos que desnaturalizem a truculência e promovam a profissionalização/humanização desse grupo profissional (COSTA, 2004).

A violência é, em última análise, expressão dos modos históricos de organização e gestão da vida em sociedade, sendo as minorias de poder seus alvos mais vulneráveis (ARAÚJO, 2002; FRANCISCHINI, SOUZA NETO, 2007). Importante lembrar que as mudanças no plano diretor municipal interessavam a investidores com alto poder aquisitivo e o sujeito agredido pode ter sido tomado como oriundo de extratos sociais de baixa renda por se posicionar contrariamente aos interesses econômicos em pauta. Ainda sobre as complexidades das violências e seus impactos, a vítima chama a atenção para o fato de que, no momento da agressão, ocupava um espaço privilegiado em nossa sociedade: o de homem, branco, sem deficiências, cisgênero, heterossexual e oriundo da classe média, diminuindo a sua vulnerabilidade a outras violências e aos desdobramentos das mesmas e lhe favorecendo o enfrentamento dessa adversidade em particular. Consciente da diferença entre a sua experiência e os casos de uma série de outros manifestantes agredidos por policiais nos últimos dois anos e dos quais teve notícia, a vítima afirma:

É triste pensar que, de certa forma, sei que tenho condições melhores que maioria deles, tanto no sentido de estrutura fisica, corporal, quanto financeira e social. E até que ponto tantas outras vítimas conseguem lidar com esses traumas e não passam a ter seus direitos tolhidos de forma mais traumática que a minha. Esse pessoal precisa de ajuda, assim como os policiais precisam de preparo. (ORLANDI, ROSA, 2014, p. 01) 


\section{Considerações finais}

A partir do que foi exposto, constatou-se que o autor/entrevistado foi vítima de grave violência física e psicológica, bem como de negligência incorrida, paradoxalmente, por servidores públicos dos quais se espera o compromisso ético de zelar pela segurança e proteção de civis. O episódio denuncia a fragilidade do processo de treinamento policial no que tange à mediação de conflitos e a dimensão ética desses saberes e fazeres profissionais.

O autor/entrevistado apresentou intenso sofrimento psicológico vinculado à grave agressão e todos os desdobramentos com os quais atualmente lida, ainda que tenham se passado trinta meses do dia da agressão. $\mathrm{O}$ ato violento feriu gravemente seu corpo, em especial a sua face, bem como a legitimidade do seu ato político. É importante ressaltar o fato de que o ato violento atingiu não só a vítima, havendo um impacto sistêmico do evento e a transmissão do traumatismo que se estendeu a toda a sua rede social, em especial à sua então esposa, que também passou a apresentar sentimentos e comportamentos que se configuram como um processo de estresse pós-traumático. Tal acontecimento ainda gera estranhamento ao manifestante haja vista a sua trajetória pacifista e humanista:

Curioso tudo isso, visto que parto de filosofias que são pacifistas por si, como o Aikido que apesar de arte marcial é considerada uma luta de não agressão e que direciona a energia do adversário para algo bom a ambos. Que tem muito em comum com a permacultura, metodologia de planejamento de ambientes humanos sustentáveis, que se utiliza da visão de problemas como alternativas e possibilidades para pensar um sistema complexo. Talvez esses dois caminhos tenham me ajudado bastante, pois ambos ensinam a transformar algo ruim em coisas úteis e que sejam boas. Ambas trabalham com "fluxos de energia", inclusive utilizam essa expressão para esse fim. A vida segue. (ORLANDI, ROSA, 2014, p. 02)

Apesar da agressão sofrida, o autor/entrevistado seguiu em frente com projetos pessoais, profissionais e inclusive acadêmicos, conferindo sentido aos períodos de recuperação pós-cirúrgicas estudando e, assim, viabilizando o seu ingresso no curso de 
doutorado. A trajetória marcada pela resiliência ${ }^{7}$ também inclui o empoderamento da vítima para seguir em frente com o processo judicial até as últimas instâncias, assim como a decisão de colaborar na escrita do presente artigo.

Esses são exemplos de estratégias voltadas à ressignificação de um acontecimento brutal, configurando-se como engajamento em uma nova causa, pois o manifestante já não é mais o mesmo e agora também empunha uma nova bandeira: a do direito à manifestação política. Tais recursos emocionais são aqui pensados como desdobramentos da dimensão ético-política da clínica psicológica, como "efeitos curativos e curadores".

No que tange às demandas por maior complexificação e humanização da capacitação policial e diante da urgência em se pensar os temas aqui levantados, a vítima sinaliza a sua disponibilidade para atuar voluntariamente no processo de formação desse grupo de trabalhadores. Nesse contexto, os autores do presente estudo vislumbram que o investimento no treinamento policial possa estender a mesma abordagem realizada com os homens adultos brancos, ricos, heterossexuais, de direita para todo o restante da população brasileira.

\section{Referências}

AMERICAN PSYCHIATRIC ASSOCIATION. DSM - IV- TR. Manual diagnóstico e estatístico de transtornos mentais. EUA, 2004.

ARAÚJO, M. de F. Violência e abuso sexual na família. Psicologia em Estudo, v.7, n.2, p.311, 2002.

BALANDIER, G. A desordem: elogio do movimento. Trad. Suzana Martins. Rio de Janeiro: Bertrand Brasil, 1997.

\footnotetext{
${ }^{7}$ O conceito de resiliência é aqui pensado como o processo de vivência de uma certa adversidade (ou um conjunto delas) marcado pelos recursos sistêmicos (subjetivos e sociais) negociados e criados por determinado sujeito, recursos esses que lhes aumentam o espaço de manobra e a potência de vida, favorecendo o enfrentamento, a aprendizagem e, em última análise, a transcendência do acontecimento trágico para seguir em frente com bem-estar e ainda mais fortalecido do que antes (MELILLO, ESTAMATTI, CUESTAS, 2005; YUNES, 2003).
} 
CASTRO, Mary Garcia; ABRAMOVAY, Miriam. Jovens em situação de pobreza, vulnerabilidades sociais e violências. Cadernos de Pesquisa, São Paulo, n. 116, p.143-176, Jul., 2002.

DELEUZE, Gilles \& GUATTARI, Félix. Kafka: por uma literatura menor. Rio de Janeiro: Imago, 1997.

CHAUÍ, M. Participando do debate sobre mulher e violência. In: CHAUÍ, M.; CARDOSO, R.; PAOLI, M. C. (Org.). erspectivas Antropológicas da mulher. Rio de Janeiro: Zahar, 1985. p. 25-62).

COSTA, N. R. da. Ofício de polícia, violência policial e luta por cidadania em Mato Grosso. Perspec, São Paulo, v.18, n.1. p.111-118, 2004/ 2007.

FALEIROS, V. P. ; FALEIROS, E. T. S. Escola que protege: enfrentando a violência contra crianças e adolescentes. Brasília: Ministério da Educação, Secretaria de Educação Continuada, Alfabetização e Diversidade, 2007.

FONSECA, Claudia. Quando cada caso não é um caso. Pesquisa Etnográfica e educação. Revista Brasileira de Educação. Jan/fev/mar/abr. 1999, n 10.

FOUCAULT, M. Microfísica do poder. Rio de Janeiro: Graal, 1979.

FOUCAULT, M. O sujeito e o poder. In: DREYFUS, Hubert L.; HABINOW, Paul; FOUCAULT, $M$. Uma trajetória filosófica: para além do estruturalismo e da hermenêutica. Rio de Janeiro: Forense Universitária, 1995. p. 231-249.

FRANCISCHINI, R.; SOUZA NETO, M. O. de. Enfrentamento à violência contra crianças e adolescentes: projeto escola que protege. Rev. Dep. Psicol. UFF , v.19, n.1, 2007.

GASPARI, E. A ditadura escancarada. São Paulo: Companhia das Letras, 2002.

GUIMARAES, J. G.; TORRES, A. R. R.; FARIA, M. R. G. V. de. Democracia e violência policial: o caso da policia militar. Psicol. estud., Maringá, v. 10, n. 2, 2005.

HELLER, A. O quotidiano e a história. Rio de Janeiro: Paz e Terra, 1972.

LÈVINAS, E. Entre nós: ensaios sobre a alteridade. Petrópolis: Vozes, 1997.

LIMA, Renato Sérgio de; SINHORETTO, Jacqueline; BUENO, Samira. A gestão da vida e da segurança pública no Brasil. Sociedade e estado, Brasília, v. 30, n. 1, p.123-144, Apr., 2015. 
MARTIN-BARBEIRO, Jesús. Ofício de Cartógrafo - Travessias latino-americanas da comunicação na cultura. Trad. Fidelina Ganzáles. Coleção Comunicação Contemporânea 3, São Paulo: Edições Loyola, 2004.

MELILLO, A.; ESTAMATTI, M.; CUESTAS, A. Alguns fundamentos psicológicos do conceito de resiliência. In: MELILLO, A.; OJEDA, E. N. S. (Orgs). Resiliência: descobrindo as próprias fortalezas. Porto Alegre: Artmed, 2005. p.59-72.

MORIN, Edgar. Os Desafios da Complexidade. In: A religação dos saberes: o desafio do século XXI. Rio de Janeiro: Bertrand Brasil, 2003.

MOURA, C. B.; HERNANDEZ, A. Cartografia como método de pesquisa em arte. 2012. Disponível em: <

http://periodicos.ufpel.edu.br/ojs2/index.php/Arte/article/viewFile/1694/1574>. Acesso em: 11 jul. 2016.

NETO, P. M. . Violência policial no Brasil: abordagens teóricas e práticas de controle. In:PANDOLFI, D.C.; CARVALHO, J.M. de; CARNEIRO, L. P.; GRYNSZPAN, M. (Orgs.), Cidadania, justiça e violência. Rio de Janeiro: Fundação Getúlio Vargas, 1999. p. 129-148.

ORGANIZAÇÃO MUNDIAL DA SAÚDE. CID-10, classificação de transtornos mentais e de comportamento da CID-10: descrições clínicas e diretrizes diagnósticas. Porto Alegre: Artes Médicas, 1993.

ORGANIZAÇÃO MUMDIAL DA SAÚDE. Informe mundial sobre la violencia y la salud. Washington, D.C.: Organización Panamericana de la Salud, Oficina Regional para las Américas de la Organización Mundial de la Salud, 2003.

ORLANDI, R.; ROSA, R. M. Laudo psicológico. Florianópolis, 2014. (Acervo pessoal),

RAYMUNDO, M. G. B. O contato com o paciente. In: CUNHA, J. A. Psicodiagnóstico - V. 5a ed. Porto Alegre: Artes Médicas, 2000.

SANTOS, José Vicente Tavares dos. A arma e a flor: formação da organização policial, consenso e violência. Tempo social, São Paulo, v. 9, n. 1, p.155-167, maio, 1997.

SAWAIA, Bader B. (Org.) As artimanhas da exclusão: análise psicossocial e ética da desigualdade social. Petrópolis, RJ: Vozes, 1999.

SAWAIA, Bader B. Psicologia social: aspectos epistemológicos e éticos. In: LANE, Silvia T. M.; SAWAIA, Bader B. (Orgs.) Novas veredas da psicologia social. São Paulo: EDUC:Brasiliense, 1995. 
SOUSA, A, M. B. Violências: o que se esconde por entre as sinuosidades do detalhe? In: SOUSA, A, M. B.; BARBOSA, I. B. (Orgs.) Cuidade da educação, cuidadar da vida. Florianópolis: UFSC-CED-NUVIC, 2011.

YUNES, M. A. M. Psicologia positiva e resiliência: o foco no indivíduo e na família. Psicol. estud. , v.8, n. especial, p.75-84, 2003.

Recebido em: 30/08/2015 Aprovado em: 07/08/2016

Universidade do Estado de Santa Catarina - UDESC Centro de Ciências Humanas e da Educação - FAED Revista PerCursos Volume 18 - Número 37 - Ano 2017 revistapercursos@gmail.com 